\title{
Los nuevos retos y tendencias del derecho administrativo en Alemania*
}

\author{
Martin Ibler* \\ Recibido: 15 de mayo de 2016 • Aprobado: 11 de junio de 2016
}

\section{Resumen}

Hoy el derecho administrativo en Alemania tiene que aportar esencialmente a superar retos nacionales, europeos y globales. La seguridad de las personas, la protección del ambiente, la creación de una infraestructura industrial y económica moderna, pero también la información, la protección jurídica y la protección de datos son algunas de las materias en las que se hace especialmente visible una necesidad de continuo desarrollo del derecho administrativo. Bajo la notable influencia del derecho europeo y del derecho internacional público, Alemania reacciona a estos retos también con ayuda de su derecho administrativo de manera diferenciada. La prevención estatal de peligros es fortalecida, para otras tareas públicas se facilita en gran medida una privatización y el Estado se limita a garantizar que los privados cumplan satisfactoriamente las tareas públicas. Una mayor transparencia de la actuación administrativa y nuevos derechos informativos deben fortalecer la protección ambiental y la aceptación de la planeación estatal de infraestructura. Se deben alcanzar todos los objetivos sin descuidar la protección de datos y la protección jurídica de los ciudadanos.

\footnotetext{
" El presente artículo es resultado de la producción académica generada por el convenio suscrito entre la Universidad Santo Tomás (sede Bogotá) y la Universidad de Konstanz - Alemania. El proyecto de investigación al que se adscribe el presente artículo es "Die Herausforderungen der Verfassung und Verwaltung gegen den Frieden und die öffentliche Sicherheit". El autor agradece la traduc-ción de Fabián Martínez Guerrero, LL. M. y doctorante en la Universidad Konstanz, y a Diana Sanabria Ramí-rez, abogada y estudiante LL.M. de la Universidad Konstanz. DOI: http://dx.doi.org/10.15332/ s1900-0448.2016.0045.07

"Profesor y exdecano de la Facultad de Jurisprudencia de la Universidad de Konstanz. Docente e investigador de la Universidad de Konstanz. Doctor Honoris Causa de la Universidad Santo Tomás. Correo electrónico: martin.ibler@uni-konstanz.de
} 
Esto se logra con la ayuda del legislativo, del ejecutivo, del judicial y de la ciencia jurídica, pues el derecho administrativo alemán cuenta con un fundamento fijo del Estado de derecho y una sistemática y dogmática acreditadas e idóneas para el futuro

Palabras clave: características del derecho administrativo, terrorismo internacional, cambio climático, privatización de tareas públicas, transparencia de la actuación ad-ministrativa.

\title{
NEW CHALLENGES AND TRENDS OF ADMINISTRATIVE LAW IN Germany
}

\begin{abstract}
In Germany, modern administrative law must be able to substantially contribute to the task of overcoming national, European and global challenges. Human safety, environ-mental protection, the development of modern economies and infrastructures, as well as the protection of information, data and rights are sev-eral fields where the need for continued development of administrative law is particularly apparent. The influence of EU law and international law is evident in Germany's reaction to these challenges, which, even with the help of its ad-ministrative law, is differentiated: Protection against threats to public safety is strengthened; other public obligations are being privatized, while the state lim-its its duties to ensuring that the private sector is fulfilling these new obligations satisfactorily. The increased transparency in administrative action and infor-mation law should strengthen both environmental protection and the approval of state infrastructure planning. All objectives should be achieved without ne-glecting citizens' rights to legal and data protection. This will be accomplished with the support of the legislation, the administration, the judicature and the scientific community, as German administrative law is based on a fundamental-ly solid rule of law and on a systematization and legal doctrine characterized by good practice and sustainability.
\end{abstract}

Keywords: characteristics of administrative law, international terrorism, climate change, privatization of public services, administrative transparency. 


\section{OS NOVOS DESAFIOS E TENDÊNCIAS DO DIREITO ADMINISTRATIVO na Alemanha}

\section{Resumo}

Hoje o direito administrativo na Alemanha deve aportar essencialmente para a superação dos desafios nacionais, europeus e globais. A segurança das pessoas, proteção do ambien-te, a criação de uma nova intraestrutura industrial e econômica moderna, mas também a informação, a proteção jurídica e a proteção de dados são algumas dos temas os quais fa-zem visível a necessidade do continuo desenvolvimento do direito administrativo. Sob a notável influencia do direito europeu e do direito internacional público, Alemanha reage a estes desafios, também com a ajuda de seu direito administrativo de maneira diferenciada. A prevenção estatal dos perigos é fortalecida, para outras tarefas publicas facilita-se em grande medida uma privatização e o Estado limita-se a garantir que os particulares cum-pram satisfatoriamente as tarefas públicas. Uma maior transparência na atuação administra-tiva e novos direitos informativos deve fortalecer a proteção ambiental e aceitação da plani-ficação estatal da infraestrutura. Devem-se atingir todos os objetivos sem descuidar a pro-teção de dados e a proteção jurídica dos cidadãos.

Isto se consegue com a ajuda do poder legislativo, executivo, e judicial e da ciência jurídi-ca, porque o direito administrativo alemão conta com um fundamento fixo do Estado de direito e uma sistemática e dogmática acreditada e idônea para o futuro.

Palavras-chave: características do direito administrativo, terrorismo, internacional, mu-dança climática, privatização das tarefas públicas, transparência da atuação administrativa.

\section{Introducción}

No solo fenómenos nacionales sino también la globalización y la europeización influyen el régimen jurídico del derecho administrativo alemán. Es en este sentido que por medio de las presentes páginas se pretende una aproximación teórica al derecho administrativo alemán y al desarrollo de algunos retos frente a los fenómenos referenciados anteriormente.

La metodología empleada para el presente documento es cualitativa en razón a que describe una situación jurídica que influye en el marco normativo del derecho administrativo alemán. 


\section{A. Concepto, objetos, objetivos, características, estructuras y contenidos del derecho administrativo en Alemania}

\section{Concepto y objetos}

En Alemania el derecho administrativo (solo) se refiere al derecho de la administración pública (no privada). Éste abarca las reglas jurídicas sobre la organización, las tareas, las competencias y los deberes de las autoridades administrativas estatales y municipales sobre su procedimiento administrativo y sobre su control. Además, se cuentan dentro de los objetos del derecho administrativo los derechos subjetivos públicos del individuo frente a la administración y la protección de estos derechos por medio de tribunales administrativos.

\section{Objetivos y características}

El derecho administrativo en Alemania debe asegurar en especial la legalidad de todo el actuar de la administración pública (Schmidt-Assmann, 2003, p. 55). Ninguna medida soberana de la administración tiene permitido vulnerar una ley (prevalencia de la ley). Todo acto soberano gravoso de la administración requiere una autorización legal (reserva de ley) (Maurer, 2011, pp. 149 y ss.). Ambos principios rigen para la asíllamada administración de intervención, con la que el Estado hace frente al ciudadano, en especial con prohibiciones y mandatos. Por el contrario, si la administración simplemente rinde prestacio-nes, sin intervenir en los derechos del ciudadano (lo que se conoce como la administración de servicios), aquella solo debe evitar vulnerar una ley. Así, para la prestación de un simple servicio la administración no necesita, en prin-cipio, una autorización legal expresa.

Estas reglas se han desarrollado en Alemania desde el establecimiento de tribunales administrativos hace 150 años (Ibler, 2007, pp. 6 y ss.). Hoy se les identifica como una característica del principio del Estado de derecho (Art. 20 párr. 3, Ley Fundamental - LF). Estos han sido formados y complementados no solo por medio de la Constitución y las leyes, sino también mediante la ju-risprudencia y la ciencia jurídica. Ejemplos de esto son la garantía de protec-ción jurídica, el principio de 
proporcionalidad y el principio de protección a la confianza. Estos principios, además de servir a la legalidad de la administración, sirven para otros dos objetivos del derecho administrativo: la seguridad jurídica y la protección jurídica del ciudadano frente al poder público.

Para estos objetivos también se continúa desarrollando permanentemente, caso a caso, la dogmática del derecho administrativo, es decir, sus conceptos reconocidos, reglas fundamentales y teoremas, ${ }^{1}$ así como los métodos de la aplicación de la ley intervinientes en su formación: junto con los métodos tradicionales de interpretación (literal, sistemática, teleológica, histórica), también se ha recurrido a nuevos métodos, a saber, la interpretación conforme a la Constitución, la interpretación conforme al derecho europeo y la así llamada prevalencia de aplicación del derecho europeo. Hoy vemos en Alemania el derecho administrativo como derecho constitucional "concretizado" ("Verwal-tungsrecht als konkretisiertes Verfassungsrecht") (Werner, 1959, pp. 527 y ss.); algunas veces se habla también del derecho administrativo como derecho eu-ropeo concretizado. De manera general puede decirse que el derecho administrativo ha juridizado de manera cada vez más fuerte el comportamiento de las autoridades. Esto se muestra de forma especialmente clara con la asíllamada discrecionalidad de la administración. La que antes fuera una discrecionalidad libre de la administración ya no existe hoy en día de esa manera. En su lugar, la discrecionalidad administrativa ha sido restringida por muchos límites jurídicos a la discrecionalidad. El respeto de estos límites puede ser con-trolado por los tribunales para la protección de los ciudadanos (Maurer, 2008, pp. 36 y ss.). Un desarrollo comparable hacia la "juridización” se observa en decisiones importantes de la administración que requieren una planeación y una ponderación; así, por ejemplo, están la planeación de proyectos de infraestructuras, como áreas de vivienda, autopistas, vías férreas, aeropuertos, depósitos de basura o grandes líneas de transporte de gas o de transmisión de energía eléctrica.

\section{Estructuras y contenidos}

El derecho administrativo alemán está bien sistematizado. Se divide en el derecho administrativo general y en las muchas áreas del derecho administrativo

${ }^{1}$ Más sobre el concepto y la gran importancia de la dogmática para el ordenamiento jurídico alemán cfr. Ibler (2010, pp. 91, 92 y ss.). 
especial, de las cuales solo quiero enumerar aquí algunas, por ejemplo, el derecho de la prevención de peligros, el derecho municipal, el derecho público económico, el derecho ambiental administrativo, el derecho de planeación, el derecho de protección de datos, el derecho administrativo laboral, el derecho escolar y el derecho de las universidades.

\section{Derecho administrativo general (incluyendo el derecho procesal administrativo)}

El derecho administrativo general abarca las regulaciones, los principios, conceptos, instrumentos y las instituciones jurídicas comunes, típicas para todas las ramas (materias) del derecho administrativo especial. Son ejemplos típicos las reglas sobre el instrumento de acción más importante para la administración alemana: el acto administrativo y sobre el instrumento no tan importante en Alemania del contrato administrativo. El derecho de la responsabilidad del Estado forma parte del derecho administrativo general, pues, con su actuar soberano, las autoridades pueden causar daños a personas en cualquier área de la administración por medio de errores y, dado el caso, tienen que indemnizar o reparar los perjuicios.

Los motores que impulsaron el desarrollo del derecho administrativo general en Alemania a finales del siglo XIX y principios del XX fueron principalmente la jurisprudencia (p. e., del Tribunal Administrativo Superior de Prusia) y la ciencia jurídica (p. e., por medio de Otto Mayer). Recién en la segunda mitad del siglo $\mathrm{XX}$, el legislador codificó partes importantes del derecho administrativo general, ante todo en leyes de procedimiento administrativo para la Federación y para los estados federados (1976) así como en la Ley Federal de Ordenamiento de la Jurisdicción Administrativa (1960). También existen principios generales del derecho administrativo reconocidos jurisprudencialmente o por el derecho consuetudinario. De acuerdo con uno de estos principios generales del derecho administrativo, por ejemplo, todo ciudadano puede exigir que la administración suprima las consecuencias de un comportamiento de la autoridad que lo afecte y que sea contrario a derecho (la así llamada pretensión de supresión de las consecuencias). Puesto que el derecho administrativo ha sido desarrollado, probado y consolidado por más de ciento cincuenta años, pocas veces sucede que esta estructura fundamental del derecho administrativo tenga que ser adaptada a nuevos desarrollos y desafíos. 


\section{Derecho administrativo especial}

El derecho administrativo especial puede reaccionar más rápidamente a nuevos retos y tendencias; además, regula materias especiales, como la prevención de peligros, la protección ambiental, la administración económica, la planeación de áreas de vivienda, calles, aeropuertos, la protección de datos, etc. Para ese tipo de materias especiales, más bien concretas, ha de reconocerse una necesidad de cambio eventual más temprana que para el derecho administrativo general, independiente de materias particulares. La administración, la jurisprudencia, la legislación y la ciencia jurídica encontrar, con la misma facilidad y rapidez, "pequeñas" soluciones a las respectivas materias especializadas. Por esta razón, el Estado modifica primero, frente a nuevos desafíos, el área respectiva del derecho administrativo especial, por ejemplo, por medio de una nueva norma jurídica específica para ese campo, mediante una modificación de la jurisprudencia o con un cambio en la práctica administrativa. Solo algunas veces las reorganizaciones en una rama del derecho administrativo especial también hacen que ciertas modificaciones en el derecho administrativo general o incluso en el derecho constitucional sean necesarias, esto depende de la dimensión eventual de los nuevos desafíos.

\section{B. Retos actuales y tendencias de desarrollo}

Quisiera a continuación sistematizar los retos actuales del derecho administrativo alemán para el presente texto en tres tipos de desafíos: globales, continentales europeos y fundamentados en el Estado nacional. Estos, sin embargo, no son independientes entre sí, sino que se articulan mucho unos con otros, en especial los desafíos globales y los continentales influyen también sobre los que en principio estarían fundamentados en el Estado nacional. Esto también es válido para las tendencias de desarrollo del derecho administrativo que reaccionan a estos desafíos.

\section{Desafíos globales}

Los desafíos globales del derecho administrativo afectan, además de a Alemania, a todos los demás Estados y comunidades de Estados. Entre tales desafíos han de ser mencionados, ante todo, el terrorismo internacional y el cambio climático. El rápido desarrollo tecnológico, por ejemplo, por el internet, puede comprenderse 
también como un desafío global. Otro nuevo reto es el actual alto flujo de migrantes; su categorización como global, continental europeo o nacional todavía no es segura. Los refugiados (en 2015 más de un millón) (Bundesministerium des Innern, s. f.) provienen de Afganistán, Libia y África, entre otros, y su destino es Europa, en especial, es Alemania. A diferencia de otros gobiernos, el alemán está preparado para la acogida de muchos refugiados de guerra, de manera que ha hecho de este desafío un desafío nacional, a lo que me referiré posteriormente.

\section{Terrorismo internacional}

Hablamos de terrorismo internacional a más tardar después de los atentados del 11 de septiembre de 2001 (Cfr. p. e. Isensee, 2004, pp. 119 (121)). Se trata de la planeación y ejecución de actos de violencia por criminales que actúan de manera global; el objetivo, la forma y dimensión de sus actos son, en bue-na medida, impredecibles.

Para combatir el terrorismo internacional, hemos fortalecido las competencias de intervención de las autoridades de policía en el derecho de la prevención de peligros (conocido en Alemania como "derecho de Policía"). A manera de ejemplo, con mayor frecuencia que antes del 11 de septiembre de 2001, la Policía puede verificar la identidad de personas, vigilar plazas públicas por medio de videos, inspeccionar domicilios o intervenir las telecomunicaciones de las personas (véase, p. e. Lorenz, 2010, pp. 41 y ss.). La ampliación de las competencias de la Policía cambia igualmente y de manera irremediable la protección de datos, que también es una materia del derecho administrativo especial. Para la lucha contra el terrorismo internacional no solo se modificaron el derecho administrativo y el derecho penal, sino también el derecho constitucional. Desde 2006, la Constitución contiene nuevas bases de competencias para la expedición de leyes federales para la lucha contra el terrorismo internacional (Art. 73 párr. 1 no. 9a LF). Las modificaciones legislativas en el derecho administrativo -y en el derecho penal- facilitan a la administración, por ejemplo, la vigilancia de la telecomunicación de los ciudadanos. Entre otras tareas, el prestador de servicios de telecomunicaciones está obligado por ley a entregar ciertos datos que guarde de sus clientes a solicitud de las autoridades (cfr. § 113 Ley de Telecomunicaciones). Como contraprestación, el Tribunal Constitucional Federal desarrolló un nuevo derecho fundamental para asegurar una mejor protección del ciudadano frente a la investigación por parte del Estado, "el derecho a la 
confidencialidad e integridad de los sistemas técnicos que debe proteger de mejor manera los datos privados en redes informáticas como el Internet. En Alemania, las autoridades administrativas y los tribunales administrativos están vinculados directamente a éste como a cualquier otro derecho fundamental (cfr. Art. 1 párr. $3 \mathrm{LF}$ ); de esa manera caracteriza el derecho administrativo moderno ${ }^{2}$. El Tribunal Constitucional Federal Alemán también tiene en la mira la protección frente al terrorismo internacional. En un fallo reciente, el Tribunal declaró parcialmente constitucional una ley con la que se autoriza a la Oficina Federal de Investigación Criminal a implementar medidas de vigilancia (por ejemplo, vigilancia dentro de la vivienda, registros online, vigilancia de telecomunicaciones), si con ello deben ser combatidos los peligros del terrorismo internacional (Sentencia del 20 de abril de 2016). Sin embargo, el Tribunal Constitucional Federal Alemán exige que la ley cumpla con las condiciones del principio de proporcionalidad. Este principio, que en Alemania se origina del derecho administrativo, se ha desarrollado desde hace rato también como principio del derecho constitucional, a saber, como parte del mandato del Estado de Derecho de la Constitución (Art. 20 inciso 3).

\section{Cambio climático}

Otro desafío global, también para el derecho administrativo, es el cambio climático. Se trata del progresivo aumento de la temperatura del planeta, fenómeno por el cual se hace corresponsable al género humano.

En la lucha contra el cambio climático, Alemania contribuye por vía del derecho internacional público, del derecho europeo y del derecho constitucional y administrativo nacional. En el derecho internacional público, Alemania ha suscrito, entre otros, la Convención Marco de las Naciones Unidas sobre el Cambio Climático de 1992 y el Protocolo de Kioto (sobre el cambio climático) de 1997. En el derecho europeo, Alemania ha contribuido a que la Unión Europea supranacional, que originalmente solo era una comunidad económica, haya adquirido en 1987 una competencia para la protección ambiental. Como todos los Estados miembros, Alemania está obligado desde ese entonces a trasponer las disposiciones jurídicas ambientales al derecho alemán. Independientemente de esto, en 1994 Alemania adoptó en su Constitución la protección ambiental como un objetivo estatal ${ }^{3}$.

\footnotetext{
${ }^{2}$ Sobre el efecto vinculante de los derechos fundamentales en Alemania véase Ibler (2003, pp. 83 (85 y ss.)).

${ }^{3}$ Art. 20a LF, agregado por la Ley modificatoria de la Ley Fundamental, No. 42, Boletín oficial (BGB1.) I 1994, pág. 3146.
} 
La trasposición de disposiciones del derecho internacional público y del derecho europeo sobre la protección del clima al derecho nacional se produce, por lo general, en el derecho administrativo especial. O bien se modifican leyes existentes, p. e. el Código de Urbanismo, la Ley Federal sobre Protección frente a Inmisiones y los reglamentos municipales de los estados federados, o bien se crean nuevas leyes, $p$. e., la Ley de Negociación sobre Emisión de Gases de Invernadero. La protección ambiental es, de esta manera, una materia "transversal" del derecho administrativo alemán, incluso se podría hablar de una nueva rama del derecho administrativo: el derecho administrativo de la protección climática.

\section{Desafíos de carácter continental europeo}

Ahora me enfocaré en los desafíos continentales europeos. Por ellos entiendo los que afectan a Alemania, en especial por su ubicación en el centro de Europa. Se deben resaltar dos desafíos aquí: la reunificación de Alemania desde el año 1990 y, empezando ya en 1952, la unificación de Europa hasta convertirse en la Unión Europea.

\section{La reunificación alemana}

Quizá el mayor desafío de los últimos veinticinco años para el ordenamiento jurídico alemán -y en especial para el derecho administrativo- haya sido la reunificación alemana (Maurer, 2011, pp. 68 y ss.). Con la caída de la socialista República Democrática Alemana tuvo que erigirse una administración y una jurisdicción administrativa conforme al Estado de derecho para cinco nuevos estados federados. Después de cuarenta años de socialismo en la zona oriental de Alemania, es decir, en cerca de un tercio del actual territorio de la República, también la economía, la industria, las infraestructuras, las ciudades y el ambiente se encontraban en un estado desolador. Para la reunificación tuvieron que crearse nuevas áreas industriales y comerciales, así como espacios urbanizables, y también hubo que reparar daños ambientales. Al mismo tiempo, fue necesario recomponer prácticamente todas las vías. Ante todo, hubo la necesidad de construir nuevas autopistas, vías férreas y aeropuertos.

El derecho administrativo de la República Federal de Alemania en 1990 solo era parcialmente adecuado para esta descomunal tarea. En la altamente industrializada 
República Federal de finales de la década de los 80, con sus modernas y efectivas infraestructuras, eran más importantes otras necesidades de los ciudadanos. En los estados federados occidentales, con poca frecuencia se requerían nuevos proyectos de infraestructuras, además, la protección jurídica del ciudadano y del ambiente se había desarrollado tanto, que la planeación y realización de, por ejemplo, nuevas autopistas y aeropuertos podía durar entre diez y veinte años ${ }^{4}$. No se podía esperar tanto tiempo para la reconstrucción de los nuevos estados federados. Por eso, después de la reunificación se crearon regulaciones de excepción. Una Ley de Aceleración de las Vías de Tráfico Vehicular y una Ley de Simplificación de la Planeación complementaron el derecho administrativo y el derecho procesal administrativo. Con su ayuda, los cinco nuevos estados federados han alcanzado al día de hoy una fuerza económica competitiva y una infraestructura casi tan buena como la de los once antiguos estados federados; algo similar se presenta con el estado de la protección ambiental. El éxito de estas reglas de aceleración fue tan grande que se les extendió a los antiguos estados federados. Sin embargo, la aceleración se consigue a costa de una protección jurídica efectiva de los ciudadanos frente a grandes proyectos de infraestructura. A esto se añade que en Alemania muchas personas son más críticas que antes frente a los grandes proyectos de infraestructura. Esto se observa en las manifestaciones de los así llamado "ciudadanos enfurecidos" contra la readecuación de la estación central de trenes de la capital del estado federado Baden-Württemberg (proyecto "Stuttgart 21"). Una tarea actual del derecho administrativo consiste, por tanto, en mejorar la transparencia de los procedimientos de planeación y la efectividad de la protección jurídica contra ellos.

\section{La participación (membresía) de Alemania en la Unión Europea}

El segundo reto continental para el derecho administrativo alemán es la unidad europea (Maurer, 2011, pp. 70 y ss.). Alemania ha sido, desde el principio, uno de los actores principales. La Constitución alemana, la Ley Fundamental, en su preámbulo y en el artículo 23 contiene y precisa el mandato constitucional de contribuir al desarrollo de la Unión Europea. En el transcurso de décadas nuestro Estado ha transferido, como todos los otros Estados miembros de la Unión Europea, cada vez más derechos soberanos a esta organización supranacional. Esta

\footnotetext{
${ }^{4}$ Sobre la planeación de infraestructura en Alemania véase Sigel (2003, pp. 151 y ss., y Lorenz (2010, pp. 9 (18)).
} 
comunidad jurídica se ha fortalecido, pasando de ser una comunidad económica a una Unión que hoy tiene permitido fijar el derecho en numerosas materias, en especial el derecho administrativo. Denominamos este derecho de la Unión Europea (como un sinónimo) entre otros como "derecho comunitario", "derecho de la unión" o "derecho europeo".

Hoy en día la mayoría de las ramas del derecho administrativo especial y gran parte del derecho administrativo general son marcadas por el derecho de la Unión Europea. El derecho ambiental muestra esto de manera especialmente clara. Las normas jurídicas que son expedidas por la Unión Europea en virtud de su competencia ambiental no solo dan una dirección al derecho de la protección de la naturaleza, sino también, por ejemplo, al derecho urbanístico nacional, al derecho de la planeación, al derecho económico nacional y al derecho procesal administrativo nacional. A causa de las disposiciones de derecho europeo ya no se puede planear y materializar un gran proyecto de infraestructura sin una prueba de tolerabilidad ambiental. En contra de tales proyectos, anteriormente los ciudadanos directamente afectados solo podían demandar violaciones a derechos propios ante los tribunales administrativos; actualmente también pueden hacerlo las organizaciones de protección del medio ambiente (p. e., las asociaciones de protección ambiental), incluso cuando no se les vulnera ningún derecho. La Unión Europea ha obligado a Alemania a la expedición de una Ley de Recursos Jurídico-Ambientales.

A causa de la unificación de Europa, Alemania requiere todavía muchas nuevas instalaciones para el tráfico a pesar de que el país tiene una red de carreteras que tan densa y tan desarrollada como en pocos países. No obstante, por su ubicación en el centro de la Unión Europea, Alemania se ha convertido en un país de tránsito para el tráfico entre Europa Oriental y Occidental. Por cuarenta años la cortina de hierro impidió el tránsito este-oeste. Después de la caída del bloque oriental y, ante todo, debido a las consecuentes am-pliaciones hacia el este de la Unión Europea (2004 y 2007) y a la inclusión de Croacia en 2013 como el vigésimo octavo miembro de la Unión, se han tenido que planear y construir nuevas autopistas, líneas férreas y canales fluviales de este a oeste. Para ello, el derecho administrativo ha debido diseñar para el futuro y de manera más efectiva los instrumentos de actuación de la administración, en especial sus instrumentos de planeación, pero también la protección jurídica del ciudadano. 


\section{Retos (jurídico-políticos) nacionales}

Ahora trataré los desafíos nacionales para el derecho administrativo. Por ellos entiendo aquí los retos que mayoritariamente se han producido "en casa", es decir, por cuenta y bajo la responsabilidad propia del Estado alemán. Estos retos pueden y tienen que ser superados por el Estado alemán y con sus propios medios. Se trata con esto en especial de determinadas desarrollos jurídico-políticos, de los que quisiera mencionar especialmente tres: primero la privatización y la transformación del Estado en un Estado garante; segundo, la exigencia de transparencia de la actuación administrativa; y tercero, el abandono de la energía nuclear como fuente de abastecimiento. Al final, daremos una pequeña mirada a la disposición del Gobierno alemán de acoger bastantes refugiados de guerra, diferente de lo que hacen muchos otros Estados.

\section{Privatización y transformación del Estado en un Estado de garantías}

Desde hace cerca de veinte años la privatización de tareas públicas transforma el derecho administrativo alemán. La privatización se basa en la idea de que los particulares, con su iniciativa y sus recursos, frecuentemente pueden cumplir las tareas públicas de mejor manera que las autoridades administrativas. Como consecuencia, el Estado se ha desprendido parcial o completamente de muchas tareas que en Alemania eran cumplidas de manera soberana y que han sido dejadas en cabeza de empresarios particulares. Tales casos se encuentran en el manejo de basuras, en las empresas municipales de transporte, en los cementerios, las empresas de energía, el correo, las telecomunicaciones y en los trenes. Incluso la privatización de cárceles se discute y se realiza en ciertos sectores por ejemplo, ayudantes de vigilancia en caso de libertad condicional, talleres, lavandería, cantina.

Aun cuando el Estado, por razones de orden constitucional, no siempre pueda sustraerse completamente de la responsabilidad, debe serle permitido no cumplir determinadas tareas públicas directamente, es decir, "por su propia mano". En lugar de esto, el Estado tendría que poder asegurar -"garantizar"- que los empresarios privados cumplan de manera satisfactoria con las tareas estatales que han asumido y que antes desarrollaba el Estado. Conforme a esta concepción, en tales casos se distribuye la responsabilidad por una tarea pública entre el Estado y los ciudadanos. El empresario privado tiene una "responsabilidad de cumplimiento", 
el Estado solo una "responsabilidad de garantía". La administración estatal restante sería una "administración de garantía" en un "Estado garante". De esta manera se desplaza el punto de gravedad de la responsabilidad estatal; esto implica una pérdida de control estatal. En el lugar de la administración estatal de servicios para la previsión de asistencia social se ubica la privatización la vigilancia de empresarios privados, es decir, solo una prevención de peligros por medio de la administración de intervención.

Las consecuencias para el derecho administrativo son considerables. Ciertas ramas del derecho administrativo tienen que ser rediseñadas, por ejemplo, el derecho de la adjudicación de contratos públicos (derecho de la contratación estatal). Pero también deben crearse ramas completamente nuevas del derecho administrativo, por ejemplo, cuando por medio de la privatización el Estado renuncia a un monopolio administrativo como en la privatización (de tareas) de las vías de transmisión en la industria de telecomunicaciones (desde 1998). Cuando para determinadas tareas públicas en lugar de las autoridades administrativas actúan particulares que son vigilados por el Estado, muchas cuestiones tienen que ser reguladas de nuevo. ¿Qué tareas públicas pueden ser dejadas en manos de los particulares? ¿Qué particulares pueden actuar? ¿Conforme a qué leyes? ¿Bajo qué condiciones? ¿Con qué competencias? ¿De qué manera? ¿Bajo qué forma jurídica tienen permitido actuar? ¿Tienen que considerar intereses sociales? ¿Cómo vigila el Estado de garantía a los privados cuando cumplen funciones públicas? ¿Debe estar permitida una libre competencia?:Debe procurarse una competencia ilimitada o debe el Estado garante procurar la igualdad de oportunidades? ¿Cómo debe ser diseñada, dado el caso, la protección jurídica de los competidores? ¿Qué protección reciben los ciudadanos frente a empresarios privados que cumplen tareas públicas? ¿Existe una protección jurídica frente al Estado garante? y de ser así, ¿¿cuál?

Para la solución de tales preguntas, desde hace algún tiempo y como consecuencia de las privatizaciones existe un "derecho administrativo sobre las consecuencias de la privatización”. Esta nueva rama del derecho administrativo (económico) se llama derecho administrativo de regulación. Regulación significa aquí una forma especial de dirección administrativa con posterioridad a la privatización de funciones. El derecho administrativo de la regulación fundamenta por primera vez para la tarea pública que antes era cumplida por el Estado, una competencia entre empresarios privados que contiene y limita esta competencia. Además, el derecho de la regulación abarca todas las formas de acción típicas (p. e., licencias) y todas 
las formas de organización (p. e., "autoridades de regulación"). Algunos ven en la administración de regulación incluso ya una nueva forma de administración junto con la administración de intervención, la de servicios y la de planeación.

\section{Transparencia de la actuación administrativa}

Otro desafío nacional para el derecho administrativo alemán atañe a la transparencia de la actuación administrativa. Aquí las leyes nacionales han provocado un cambio en la cultura administrativa estatal. Los procedimientos de las autoridades, que antes estaban marcados por la confidencialidad, son reorganizados para una administración transparente. Actualmente no solo las personas que están involucradas en un determinado procedimiento administrativo, por ejemplo, como solicitantes, pueden inspeccionar los archivos administrativos. Por el contrario, nuevas leyes de información de la Federación y de once de los dieciséis estados federados garantizan a cualquier persona un derecho a cualquier información que posea una autoridad. Solo excepcionalmente -por ejemplo, por razones de la protección de datos- puede negarse este de-recho. Además, algunas de las nuevas leyes obligan en gran medida a las autoridades a publicar información, por ejemplo, en registros de información en Internet (principio del Open Government o gobierno abierto).

La transparencia de la Administración ordenada por ley no se inserta sin complicaciones en el derecho administrativo alemán. Surgen tensiones en especial con la protección de datos, que también ha sido prevista por ley, pero asimismo con la reserva de la competencia en la adjudicación de contratos públicos, requerida por ley. $\mathrm{Si}$, por ejemplo, una autoridad en un procedimiento para la adjudicación de un contrato público tuviera que hacer accesible para cualquier persona las ofertas de cada uno de los oferentes, los propósitos del derecho de la contratación -protección de la competencia y cuidado de los recursos presupuestales del Estado- se frustrarían. Sin embargo, estas tensiones se podrán superar con la ayuda de la dogmática del derecho administrativo y de la jurisdicción administrativa.

\section{Abandono de la energía nuclear}

Permítanme aludir todavía a un tercer desafío para el derecho administrativo alemán. Su detonante fue la catástrofe atómica de Fukushima el 11 de marzo de 2011. Movido por la catástrofe en Japón, el Gobierno alemán anunció el abandono de la energía nuclear como fuente de abastecimiento en Alemania. Ese anuncio 
llegó de manera sorpresiva, pues recién en otoño de 2010 se había ampliado el período de funcionamiento de las plantas de energía nu-clear existentes (para algunas hasta 2036). En el año 2012, la proporción de energía nuclear dentro de la producción eléctrica total en Alemania era de un $16,1 \%$. Si ha de ser reemplazada por una energía amigable con el medio ambiente, debe obtenerse en Alemania más electricidad de la energía eólica. Por el contrario, la energía solar en Alemania, condicionada por el clima, aún no basta como reemplazo a pesar de que la técnica solar avanza cada vez más. No obstante, la energía eólica puede obtenerse sobre todo en el norte de Alemania. Por esta razón, en poco tiempo se planearon y erigieron grandes parques de energía eólica en el mar del Norte y en el Báltico. Desde allí se debe transportar la electricidad al interior del país, y es ahí donde radica el problema: muchas regiones metropolitanas y una gran parte de los grandes consumidores industriales de energía se encuentran en el sur de Alemania, por eso se necesitan largas líneas de interconexión eléctrica para conexiones de 380 kilovoltios en total, hasta 3600 kilómetros.

La ampliación expedita necesaria de esta red de electricidad no solo es un desafío para los ingenieros, sino también para la administración de planeación, para el derecho administrativo y para el derecho de la organización del Estado. Las nuevas conexiones eléctricas deben atravesar varios estados federados, y para ello el Estado Federal requiere competencias de planeación especiales que no existían de esa forma en Alemania. Por eso en julio de 2011 se expidió la Ley Federal de Ampliación Acelerada de la Red de Interconexión Eléctrica, que contiene nuevos instrumentos de planeación; pero para recurrir a dichos instrumentos falta experiencia por parte de las autoridades administrativas y de los tribunales administrativos. La protección ambiental y la protección jurídica de los ciudadanos pueden debilitarse por ello. Además de lo anterior, se añade que las redes eléctricas se encuentran en manos privadas; el control estatal se limita a una administración de garantía.

\section{Sobre la crisis migratoria en Europa}

La discutida decisión política del Gobierno alemán, en especial de la Canci-ller, de acoger en Alemania refugiados de guerra a gran escala pone a la administración alemana en un considerable reto. Las leyes hasta el momento y la praxis de la administración no son suficientes para ello. Por ejemplo, tiene que lograrse alojamiento para cientos de miles de refugiados, para lo cual se necesitan nuevas áreas 
urbanas, incluso ahí donde hasta ahora no se debería habitar, por ejemplo, en zonas industriales y en las afueras de los municipios, aunque en la Alemania densamente poblada (229 habitantes por km2) deberían, por fuerza de ley, mantenerse libres por protección de la agricultura y de la naturaleza. El legislador reaccionó rápido en las materias administrativas de la construcción, de la planeación, de las comunas y de la protección de la naturaleza, modificó el Código de Urbanismo y rompió con ello reglas de hace décadas sobre la planeación general de organización urbana. El legislador también tiene que modificar leyes para la administración de asilo, para la administración social, para la policía y para otros sectores de la administración. De nuevo se confirma la observación mencionada al principio acerca de que el Estado puede reaccionar con especial efectividad y rapidez frente a desarrollos sorpresivos con modificaciones del derecho administrativo especial.

\section{Conclusiones}

Hoy el derecho administrativo en Alemania tiene que aportar esencialmente a superar desafíos nacionales, europeos y globales. La seguridad de las personas, la protección del ambiente, la creación de una infraestructura industrial y económica moderna, pero también la información, la protección jurídica y la protección de datos son algunas de las materias en las que se hace especialmente visible una necesidad de continuo desarrollo del derecho administrativo. Bajo la notable influencia del derecho europeo y del derecho internacional público, Alemania reacciona a estos retos también con ayuda de su derecho administrativo de manera diferenciada. La prevención estatal de peligros es fortalecida; para otras tareas públicas se facilita en gran medida una privatización y el Estado se limita a garantizar que los privados cumplan satisfactoriamente las tareas públicas. Una mayor transparencia de la actuación administrativa y nuevos derechos informativos deben fortalecer la protección ambiental y la aceptación de la planeación estatal de infraestructuras. Se deben alcanzar todos los objetivos sin descuidar la protección de datos y la protección jurídica de los ciudadanos.

Esto se logra con la ayuda del Legislativo, del Ejecutivo, del Judicial y de la ciencia jurídica, pues el derecho administrativo alemán cuenta con un fundamento fijo del Estado de derecho y una sistemática y dogmática acreditadas e idóneas para el futuro. 


\section{Referencias}

Bundesministerium des Innern (2015): Mehr Asylanträge in Deutschland als jemals zuvor.

Deutschland: Bundesministerium des Innern.

Ibler, M. (2003). La protección de los derechos fundamentales por los tribunales federales "específicos" y por la Corte Constitucional Federal. En Universidad Santo Tomás (ed.), Memorias Seminario Internacional de Derecho Alemán (pp. 83-123). Bogotá: USTA.

. (2007). Pasado y presente de la relación entre el derecho constitucional y el derecho

administrativo en Alemania. Cuadernos Constitucionales de la Cátedra Fadrique Furió

Ceriol, 50/51, 5-21. . (2010). La dogmática de los derechos fundamentales en transformación. En Á.

Echeverri (comp.), Las estructuras democráticas y el Estado actual (pp. 91-105). Bogotá: Ediciones USTA.

Isensee, J. (2004). El terror y el Estado, que aprecia la vida. Revista de la Facultad de Derecho de la Universidad de Granada, 7 (pp.119-136).

Lorenz, D. (2010). La garantía de la protección judicial y la jurisdicción contenciosoadministrativa en Alemania, Res. Pública 2 (pp. 9-20). Bogotá: Ediciones USTA . (2010). E1 registro oculto online como desafío en la dogmática de los derechos

fundamentales. En A. Echeverri (comp.), Las estructuras democráticas y el Estado actual (pp. 41-54). Bogotá: Ediciones USTA.

Maurer, H. (2011). Derecho administrativo. Parte general. Madrid: Marcial Pons. . (2008). Introducción al derecho administrativo alemán. Bogotá: Ediciones USTA.

Schmidt-Assmann, E. (2003). La teoría general del derecho administrativo como sistema. Madrid: Marcial Pons.

Sentencia del 20 de abril de 2016 (1 BvR 966 y 1140/09), Tribunal Constitucional Federal Alemán. En JURIS (base de datos jurídicos).

Sigel, K. (2003). La protección jurídica dentro del marco de derecho de planificación en Alemania. En Universidad Santo Tomás (ed.), Memorias Seminario Internacional de Derecho Alemán (pp. 151-178). Bogotá: Ediciones USTA.

Werner, F. (1959). Verwaltungsrecht als konkretisiertes Verfassungsrecht. En Deutsches Verwaltungsblatt (DVBl), 527-533. 